\title{
Research on Collaborative Development Strategies of the Tourism Logistics Industry in Wuhan
}

\author{
Liu $\mathrm{T}^{1^{*}}$, Ning $\mathrm{Y} \mathrm{H}^{2}$ \\ ${ }^{1}$ College of Business Administration, Wuhan Business University, Wuhan, China \\ ${ }^{2}$ College of Tourism Management, Wuhan Business University, Wuhan, China
}

\begin{abstract}
The new growth points of two major industries - tourism industry and logistics industry — can be fully utilized to reach the effect of $1+1>2$ by promoting their collaborative development. It is suitable to boost the tourism logistics collaborative development in Wuhan, which integrates various advantages in traffic location and resources, tourist market and industrial development, policy opportunity, etc. In this research, the tourism logistics collaborative development model in Wuhan was expounded from three aspects: planning and design of tourism logistics route, integrated design of tourist commodity logistics, and tourism waste logistics collaborative treatment system, expecting that Wuhan can grasp the opportunity and provide policy support, technical support and financial support to promote the collaborative development of the tourism logistics industry and accelerate the healthy development of Wuhan.
\end{abstract}

\section{Introduction}

As an emerging field extending from the tourism industry and logistics industry, the tourism logistics industry not only includes the flow of tourism commodities and related materials brought by tourists' consuming behavior like eating, hotel staying, traveling, touring, purchasing, entertainment, etc. on their itinerary, but also contains their demand for logistics services during their travel, and even includes the tourism and logistics information processing running throughout the whole logistics activity. In a word, it is a relevant logistics activity formed with the tourism development. Studying the collaborative development of tourism logistics industry and exploring feasible solving strategies accord with the realistic needs of Wuhan City for constructing a national central city, providing a certain reference for the development and construction of other tourism cities.

\section{Current Development Status of Tourism Logistics Industry in Wuhan}

\subsection{Current development status of the tourism industry}

According to the " $13^{\text {th }}$ Five-Year" development plan of the tourism industry in Wuhan, the tourism industry in Wuhan aims at "realizing, from global, national and regional levels, the transformation and upgrading from a nationwide tourist destination into a nationally first-rate and internationally famous tourist destination with the characteristics of waterfront tourism and leisure".
Based on the 2019 statistical information released by Wuhan Bureau of Culture and Tourism, the annual total number of tourists in Wuhan has reached $318,983,100$ by the end of 2019 , which increased by $10.8 \%$ compared with that in the previous year; the total tourism revenue was RMB $357,079,000,000$, with a growth rate of $12.9 \%$, realizing the preset economic goal in the " $13^{\text {th }}$ Five-Year" development plan of the tourism industry in Wuhan ahead of schedule and above the quota.

Up to the end of 2019, Wuhan possessed a total of 44 A-Class tourist attractions and three 5A-Class tourist attractions, ranking top 1 among national sub-provincial cities. There are 57 star-level hotels, among which 14 were five-star hotels, 15 were constructed according to the five-star standard, and the quantity and grade of star level hotels were at a moderate level among cities of the similar kind; 350 travel agencies, among which 45 had the qualifications for organizing outbound tourist groups, and 70 were A-Class travel agencies, and they ranked top five among national sub-provincial cities for both quantity and comprehensive strength.

From the above data, the comprehensive strength of tourism enterprises in Wuhan has been continuously enhanced, the tourism industry system has been increasingly perfected, and the tourism industry has become an important pillar industry and engine industry in the socioeconomic development of Wuhan.

\subsection{Current development status of the logistics industry}

In line with the " $13^{\text {th }}$ Five-Year" development plan of the modern logistics industry in Wuhan, the development 
orientation of the logistics industry in Wuhan is as follows: By the end of 2020, a modern logistics system, which drives the city circle, leads the middle reaches of the Yangtze River Economic Belt, links the east areas with the west areas, and connects the national and even global market, will have been basically completed, and by then, Wuhan will become an internationally well-known, domestically advanced and regionally leading national logistics center.

By 2019, the annual total amount of social logistics in Wuhan has reached RMB 4,000 billion, increasing by $9.7 \%$ in comparison with that in the previous year. The added value of the logistics industry was RMB 145 billion, growing by $10.8 \%$. The volume of freight transport completed throughout the year was $675,552,200$ tons, growing by $8.7 \%$; the turnover volume of freight transport was $389,718,000,000$ ton-km, with a growth rate of $7.2 \%$. The number of civil aviation flight routes in the whole city was 200, which increased by 13 compared with that in the previous year, among which 63 ones were international and regional routes, and four ones were newly opened; 137 ones were domestic routes, and 9 ones were newly opened. Sino-European (Wuhan) international block trains could reach 11 countries, adding two more countries in comparison with those in the previous year, and reach 19 cities, adding five more countries in comparison with those in the previous year.

\section{Advantages of Wuhan in Promoting the Collaborative Development of the Tourism Logistics Industry}

\subsection{Comprehensive advantages in traffic location and resources}

Wuhan, usually called "a hub linking nine provinces", is an important transportation hub in China. In recent years, it has been constructed into a national central city and port-type logistics hub, which is supported by four major functions - national economic center, high-level scientific and technological innovation center, trade logistics center and international exchange center. With abundant tourism resources, Wuhan has won the titles of national famous historic and cultural city, China excellent tourism city, etc., and has ranked top 10 among national tourism cities. As the geographic center of China's population and economy and multifunctional economic center in Mainland China, Wuhan is located at the point of intersection between the largest river, Yangtze River, and its largest branch, Hanjiang River, with high shipping value. Meanwhile, it is also the most important railway center, with both number of passengers dispatched by railway and volume of freight traffic ranking top 1 . The highly developed urban commerce, highly concentrated tourist flow, logistics and information flow, and abundant urban social resources in Wuhan can boost the development of the tourism logistics industry. Wuhan has obvious educational advantages, which is manifested by numerous colleges and universities, thus being able to transport a large number of high-quality tourism logistics talents, and moreover. tThis is conducive to the integration of the tourism logistics industry with other relevant industries and the format innovation.

\subsection{Advantages in tourist market and industrial development}

First, with a permanent resident population of over ten million, Wuhan is the largest city in Central China and also the political, economic, cultural education and transportation center in the whole province. It shows very strong attraction to the tourist market within Hubei Province thanks to the radiation effect of Wuhan " $1+8$ " city circle and "1-hour commuting circle". Second, Wuhan is the center of urban agglomeration on the middle reaches of Yangtze River. The urban agglomeration has created the economic aggregate equal to $9.6 \%$ of nationwide economic aggregate with land area and population size of $3.4 \%$ and $9.0 \%$, respectively, and the surrounding cities are in great demand for traveling to Wuhan. Third, as one of the cities with the most developed high-speed railway network in China, Wuhan is considerably attractive for various tourist markets like Southern China and Northern China based on its favorable geographic advantages and traffic convenience. To sum up, Wuhan enjoys apparent advantages in tourist markets.

From the aspect of industrial structure, the proportions of the primary industry and secondary industry are declining year by year in Wuhan, but that of the tertiary industry presents the opposite trend, and the tertiary industry has gradually developed into the key industry driving the economic growth. In the tertiary industry, the aggregate industry scale and overall industrial power of both tourism and logistics top the list throughout China, showing evident industrial development advantages.

\subsection{Advantages in policy opportunities}

In recent years, by grasping the great opportunities like creating a national central city, tourism standardization pilot city, wisdom tourism pilot city and port-type logistics hub and holding Military World Games, Wuhan has made efforts into the traffic network construction which changes with each passing day, so that its city image is continuously enhanced, the tourism environment and livable environment are obviously improved, and the suitable business atmosphere becomes increasingly thick.

To sum up, Wuhan has favorable development foundation and development advantages in both industries: tourism and logistics. Its tourism logistics industry boasts effective policies and market development opportunities with large potential demands. Under the all-for-one tourism background guided by "tourism +", which is clearly implemented according to the $13^{\text {th }}$ Five-Year tourism plan, the problems encountered in the realistic development should be pertinently analyzed and solved to comprehensively 
drive the high-speed development of the tourism logistics industry and further enhance the industrial competitiveness.

\section{Design of Tourism Logistics Collaborative Development Model in Wuhan}

\subsection{Tourism logistics route planning and design}

The development characteristics and requirements of the tourism industry and logistics industry should be fully considered in the tourism logistics system planning and design, in an effort to realize the common development of the tourism industry and logistics industry through ingenious top-level design and close cooperation between tourism enterprise and logistics enterprise. First, the logistics network can be designed based on hot tourist attractions and excellent tourist routes, and the reasonable planning through scientific big data analysis, study and judgement can not only ensure immediate supply of logistics nodes to scenic spots but also guarantee unblocked logistics route and tourist route. Second, the cooperation can be carried out with the business entities on tourist routes like accommodation, catering and supermarket by taking big data and information processing as the bond through professional third-party logistics platforms, and meanwhile, waste disposal and recycling enterprises can be involved to construct a tourism logistics collaboration platform integrating transportation of goods, warehousing \& deposition, dispatching, packaging, distribution processing, information processing and waste recycling. Second, the logistics system can be included into the design of tourism products as a kind of tourism resource. Being appropriately packaged, highly automated logistics sorting system, highly intelligent logistics tracking and data analysis system, waste material logistics recycling system that embodies the green circular economy, etc. can be forged into science popularization-type and experience-type industrial tourism and study + travel products, etc.

\subsection{Integrated design of tourist commodity logistics}

In the sightseeing process, tourist have great commodity consumption demand, which is mainly divided into two types: one is tourist commodities immediately consumed and used, including material consumption derived from eating, hotel staying, traveling, sightseeing, purchasing and entertainment processes; the other is tourist commodities consumed in a delay, such as tourist souvenirs purchased in the touring process, which need to be taken away from tourist destinations. The tourist commodities immediately consumed and used can be stably supplied to operating entities within the aforementioned tourism logistics collaboration platforms in small-batch-size and multi-batch replenishment pattern through the prediction and analysis of tourism logistics big data from tourist distributing centers, scenic spots, stations, airports, etc. The tourist commodities consumed in a delay can be directly delivered by platforms from the distributing centers, only needing the tourists to simply register and confirm the delivery time and address in offline stores of various operating entities like supermarkets during the sightseeing process. The tourists can also place orders via E-commerce pages on the platforms whenever possible. No matter such orders are placed online or offline, the tourists can conveniently inquire and track the logistics information, thus not only mitigating the replenishment pressure of offline stores but also improving the tourist consumption experience.

\subsection{Design of tourism waste logistics collaborative treatment system}

The wastes formed in the operation of tourism enterprises can be reused by classification, recycling and conversion. For instance, the kitchen wastes generated by tourism catering enterprises can be converted into energy sources and raw materials through professional kitchen waste treatment techniques; various metal wastes and waste papers, etc. can be reused after being recycled, or designed into creative works, thus becoming new tourism resources. In a scenic spot, for example, discarded optical disks and metal pop cans are spliced into various animal models through creative design, so the wastes are suddenly converted into artworks. Since the 19th National Congress of the Communist Party of China, the Central Government and local governments have always accelerated the garbage classification work, and the concepts of sustainable development and green development have been increasingly accepted. To adapt to the needs under the new situation of household garbage classification work, Wuhan has transformed the household waste management mode to reduce the generation of household garbage from sources, elevate the resource recycling rate and relieve the crisis of "garbage siege". On July 1, 2020, Wuhan started putting Regulations of Wuhan on Household Garbage Classified Management into force. As definitely required by the "ten major action plans" in the " $13^{\text {th }}$ Five-Year" tourism development plan in Wuhan, up to 2020, the household waste cleanup rate in tourist areas should reach $100 \%$, so should the rate of classified collection and hazard-free treatment. The tourism waste cleanup, classified treatment and recycling work need the collaboration among various departments and vigorous propaganda from all levels. Meanwhile, it has gradually become a consensus to include this observation point into the evaluation of scenic areas. Therefore, the tourism logistics collaboration platform should construct a tourism waste collaborative treatment system. First, the platform should cooperate with environmental sanitation department in completing the classified garbage cleanup, hazard-free treatment and cleanup should be done for unrecoverable garbage, and the recyclable wastes will enter the waste recycling system. Second, professional waste treatment enterprises can be included into the platform, the recyclable wastes should be transported to 
the waste treatment enterprises for recycling, and the generated new products can be distributed via the platform again, thus forming a scientific tourism tourist logistics collaborative treatment system. Third, after realizing large-scale development via the platform, this set of system can effectively reduce the classified waste treatment cost of operating entities inside the platform. Furthermore, this set of system itself can be created into industrial tourism products with considerable characteristics. Being opened to the public, this product can exert a very good effect of publicity, and promote the urban garbage classification work.

\section{Supporting Measures}

\subsection{Policy support}

Wuhan should provide a series of policy supports with respect to land, tax, infrastructure planning \& construction and approval procedures for the tourism logistics collaborative development model. The policy guiding and supporting effects can enhance related enterprises' enthusiasm for participation and relieve their cost burden in the initial development phase. Meanwhile, the government should provide an appropriately loose development environment for the platform development, and encourage waste treatment enterprises to station and develop on the platform through good policies.

\subsection{Technical support}

The key to the construction of the tourism logistics collaboration platform lies in the establishment of tourism logistics information and big data system. That the platform collects and analyzes various information scientifically and reasonably is a technical guarantee for the accurate prediction and smooth platform operation. In particular, attention must be paid to the boundary of data collection and use, and the relationships among safety, efficiency and privacy protection should be handled well in the construction of information system.

\subsection{Financial support}

A large amount of capital input is required in the construction process of the tourism logistics collaboration platform. On the one hand, Wuhan should deepen its understanding of difficulties faced by enterprises, enhance the financial support for the logistics development of scenic areas, and give qualified tourism logistics enterprises certain fiscal subsidies or tax reduction and exemption, so as to support their reform and development. On the other hand, the government should guide financial institutions in this area to provide complete financial services for the development of tourism logistics enterprises.

\section{Conclusion}

As the tourism industry is closely associated with the logistics industry, promoting their collaborative and comprehensive development and mutual cooperation can find their new growth points and realize the effect of $1+1>2$. Wuhan is very suitable to promote the tourism logistics collaborative development by virtue of its excellent advantages in traffic location, comprehensive resources, tourist market, industrial development and policy opportunity, along with the pioneering spirit and pursuit of excellence of this great city. In this research, the conception of tourism logistics collaborative development model in Wuhan was expounded from three aspects: planning and design of tourism logistics route, integrated design of tourism commodity logistics and tourism waste logistics collaborative treatment system. Wuhan should give full play to its own advantages, grasp the opportunities, and provide policy support, technical support and financial support to boost the collaborative development of the tourism industry and logistics industry and accelerate the healthy development of the whole city. At present, the latest achievements of a batch of information technologies and management such as wisdom tourism, cloud computing, big data, IoT and 'Internet +', are powerfully driving the reform and innovation of various fields, and boosting the continuous multi-industry integration. In the foreseeable future, the pattern of 'tourism + ' other industries will certainly become a strong economic support for many tourism cities, and 'tourism + logistics' will serve as a solid foundation for their sound and rapid economic development.

\section{Acknowledgements (Fund of the Project)}

This paper is one of the phased outcomes of Wuhan Business University General Project titled Research on Tourism Logistics Collaborative Development Strategies under the Background of All-for-One Tourism (2017KY019).

\section{References}

[1] Yang J. Study on integrated development mode of tourism logistics based on collaboration: in the case of Chengdu [J]. Logistics Technology, 2014 (09): 61-63.

[2] Xia X X. Practice teaching model research in the major of higher vocational logistics management $[\mathrm{J}]$. Logistics Engineering and Management, 2017 (12): 3-3.

[3] Yang X A. Development status and countermeasures of urban tourism and logistics industry in China based on industrial competitiveness [J]. Logistics Technology, 2014 (21): 176-178.

[4] Yang J. Study on integrated development mode of tourism logistics based on collaboration: in the case of Chengdu [J]. Logistics Technology, 2014 (5): 3-3.

[5] Li C. Enhance the molding of Zhengzhou city image [J]. Kejifeng, 2019 (12): 121-122.

[6] Ling $M$ L. Countermeasure research on the 
development of Meizhou tourist market [J]. Vacation Tour, 2019 (04): 83-84.

[7] Feng X M. Development prospect analysis of five-year higher vocational tourism education in Jiangsu Province [J]. Tourism Overview (industry edition), 2011 (09): 83-85.

[8] Tian B. Research on the sports tourism development in Xuchang $[\mathrm{J}]$. International English Education
Research: English edition, 2014 (1): 2-2.

[9] Lu F Q, Mou Z J, Xu R C. Exploration of optimal settings of undergraduate majors in colleges and universities in Inner Mongolia-based on the perspective of industrial structural adjustment [J]. Journal of Inner Mongolia Normal University (education and science edition), 2015 (09): 66-69. 